\title{
Utility of multimaterial 3D printers in creating models with pathological entities to enhance the training experience of neurosurgeons
}

\author{
Technical note
}

\author{
Vicknes Waran, F.R.C.S.(NeUrosurgery), ${ }^{1}$ \\ Vairavan Narayanan, F.R.C.S.(Neurosurgery), M.Surg., ${ }^{1}$ \\ Ravindran Karuppiah, M.Surg., ${ }^{1}$ Sarah L. F. Owen, D.Phil., ${ }^{2}$ and Tipu Aziz, F.Med.Sci. ${ }^{3}$ \\ ${ }^{1}$ Division of Neurosurgery, Faculty of Medicine, University of Malaya, Kuala Lumpur, Malaysia; ${ }^{2}$ Centre for \\ Simulation in Healthcare, University of Portsmouth; and ${ }^{3}$ Nuffield Department of Surgical Sciences, \\ University of Oxford, United Kingdom
}

\begin{abstract}
The advent of multimaterial 3D printers allows the creation of neurosurgical models of a more realistic nature, mimicking real tissues. The authors used the latest generation of 3D printer to create a model, with an inbuilt pathological entity, of varying consistency and density. Using this model the authors were able to take trainees through the basic steps, from navigation and planning of skin flap to performing initial steps in a craniotomy and simple tumor excision. As the technology advances, models of this nature may be able to supplement the training of neurosurgeons in a simulated operating theater environment, thus improving the training experience. (http://thejns.org/doi/abs/10.3171/2013.11.JNS131066)
\end{abstract}

KEY WORDS • neurosurgery $\bullet$ simulation $\bullet$ training $\bullet$ clinical skills
3D rapid prototyping

$\mathrm{F}$ INDING and developing suitable models for the purpose of training a neurosurgeon is always a challenge. There is the need for accuracy and realism, and these have to be balanced against cost, rules, and regulations. With the advent of 3D printers, models have been created using actual patient data to aid in the planning of complex surgical procedures as well as to explain such procedures to patients and their relatives..$^{1-3,6,8,12}$ However, until now most of these models have been constructed from a single material, and therefore have lacked certain details and realism. On the other hand, models with varying tissue properties described previously are expensive and difficult to make. ${ }^{5}$

We have used the latest generation of 3D printers that allow models to be created out of materials of varying consistency and density, and that have allowed us to overcome some of the aforementioned problems and simultaneously add reality to the models created. ${ }^{9}$ Using complex computer programs and manufacturing techniques on these new-generation printers has made it possible to replicate various tissue types with different tissue handling features. ${ }^{4,711,12}$ This gives room for junior trainees to be shown how to perform the necessary steps required in neurosurgical procedures.
Using these models we were able to take trainees through the basic steps, from navigation and planning of skin flaps to performing the initial steps in a craniotomy and simple tumor excision.

\section{Methods}

The CT data obtained in a patient with a cortically located brain tumor were selected, and the various tissue components (skin, bone, and dura mater as well as the tumor surrounded by normal brain) were segmented. The DICOM-format CT data were converted into STL format by using in-house software (BIOMODROID CBMTI UM), and were subsequently used to print an actual replica of the patient by using a 3D printer (Objet500 Connex; Stratasys, Ltd.).

The 3D printer was able to create various tissue types of varying consistency and density to mimic skin, bone, dura, and tumor (Fig. 1: composite cross-section). In the programming of the machine's print characteristics to mimic actual tissue handling, a number of features were considered. The "skin" needed to be pliable enough to be cut by a knife and to hold a suture. It also needed to be supple, to allow flaps to be created and self-retaining re- 


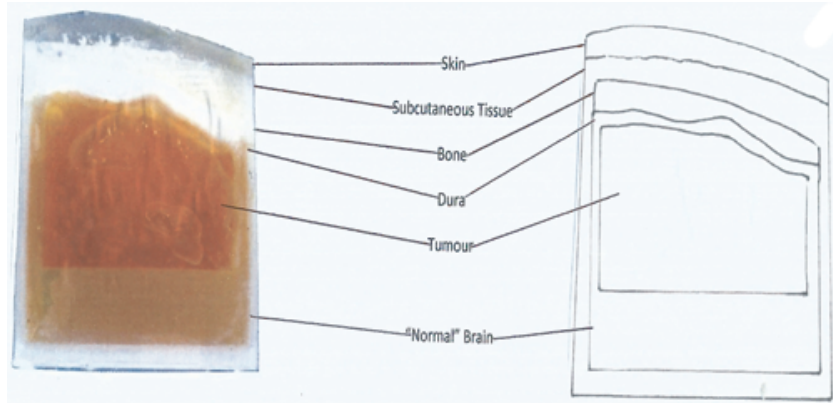

FIG. 1. Cross-sectional view of model with tumor, and drawing delineating parts of the model.

tractors to be kept in place. An interface layer was created to allow the flap to be raised from the underlying "bone" as in a real patient (Fig. 2: flap with retractor in situ).

The "bone" layer was made solid to provide the feel of using conventional perforators and bone cutters. This layer also had the necessary properties to provide the chatter created when drilling the cranium (Fig. 3: bone with perforator in place). An interface was also created between the "bone" and "dura," thus allowing the cranial perforator to stop automatically when the dural layer was encountered. This layer also allowed the foot piece of the craniotome to cut without tearing the "dura" (Fig. 4: post-bur hole with dura visible).

The "dura" was made sufficiently thin to mimic the handling of an actual dural layer, including the ability to lift it with a pair of forceps and cut it with tissue scissors. This "dural" layer was designed to be lifted off the underlying "tumor." The space occupied by the "tumor" was printed based on the actual patient's imaging data. This "tumor" was differentiated from the surrounding "brain" by creating a variation in consistency, the "tumor" being

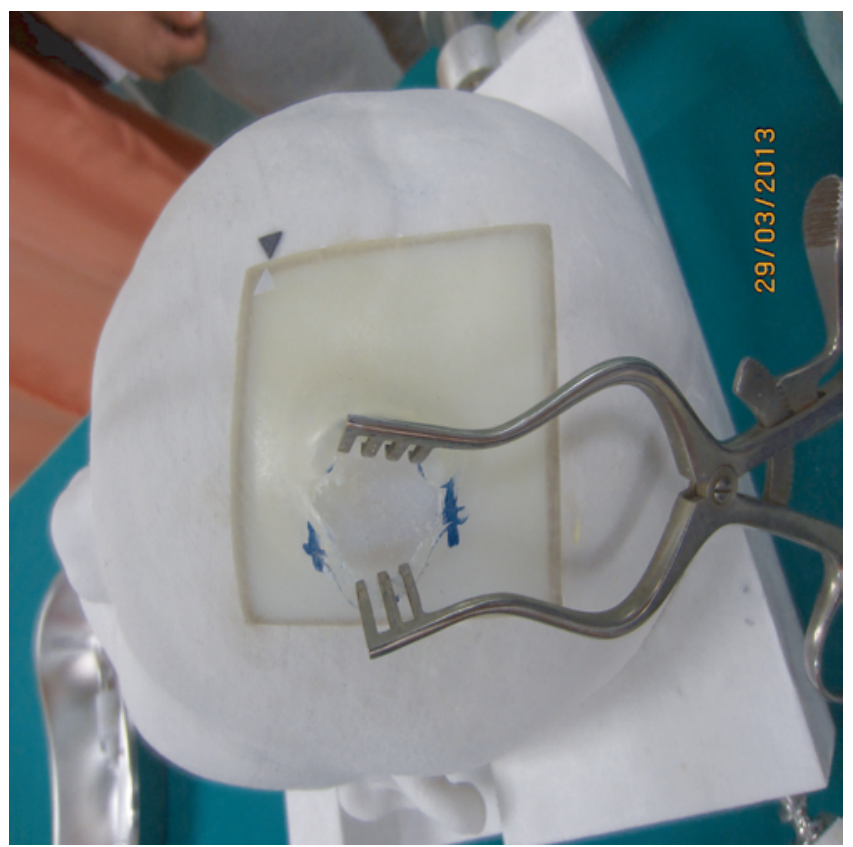

FIG. 2. Photograph showing skin flap with retractor in place.

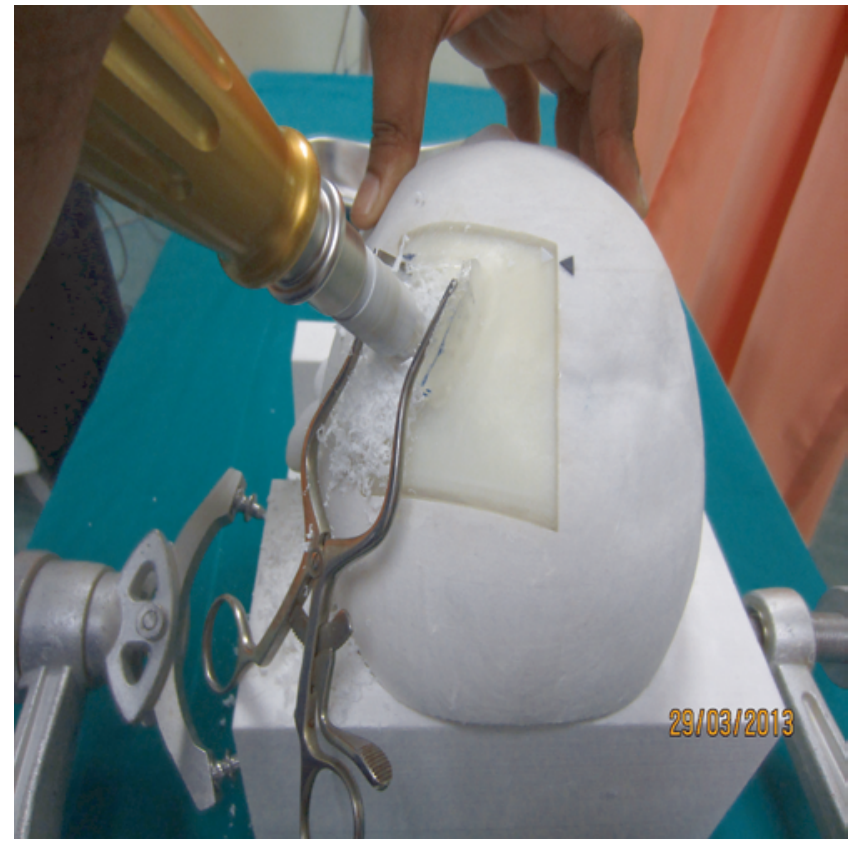

FIG. 3. Photograph showing perforator creating bur hole.

softer than the brain. The "tumor" was colored orange, whereas the "brain" was light yellow.

Finally, because this model was created based on actual patient data, it was possible to register it accurately with a navigation station (either BrainLab using the $\mathrm{Z}$ touch laser registration system or the Medtronic surfacematching technique), and a suitable flap was planned for the tumor excision.

\section{Results}

Based on the technique described above, multiple re-

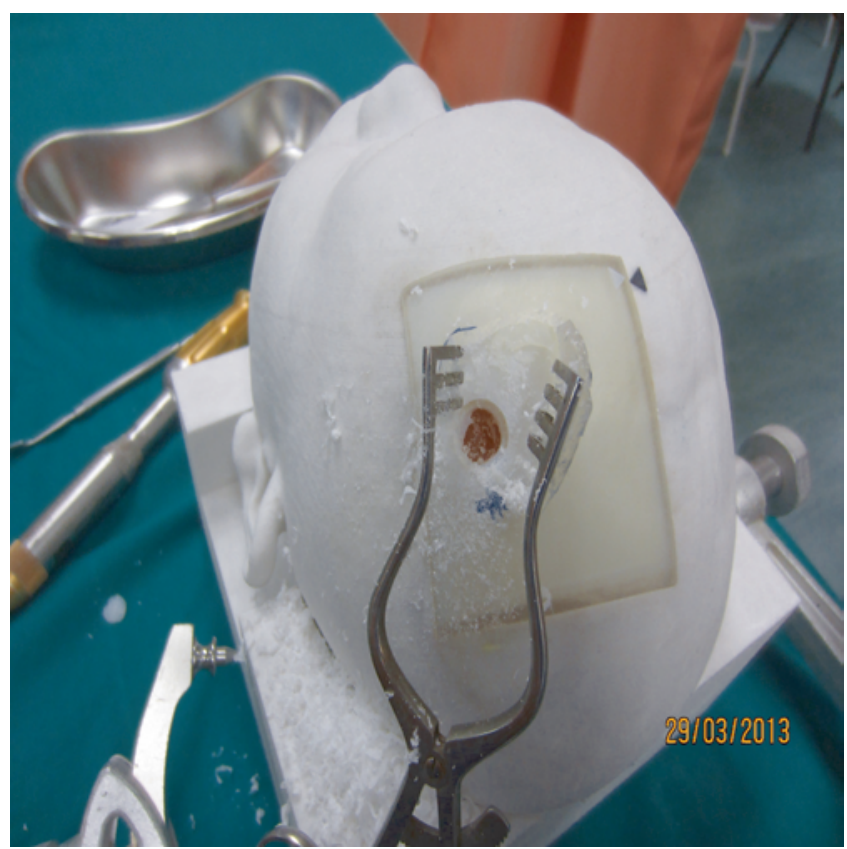

FIG. 4. Photograph showing bur hole with dura intact. 
productions of the model were built. These were tested by 3 neurosurgeons and an expert in surgical simulations, who were then questioned on the ability of the models to meet the criteria as set in the methodology section above (Table 1, Video 1).

VIDEo 1. Clip demonstrating surgical head in use. Copyright Vicknes Waran. Published with permission. Click here to view with Media Player. Click here to view with Quicktime.

\section{Discussion}

The expanded use of 3D printers in the field of medicine has led to a number of innovations, especially through the building of patient-specific models based on actual imaging data. ${ }^{8}$ A number of reports have commented on the use of these models in dissecting complex anatomical areas such as the cavernous sinus. These models were generally either constructed from a single material or required complex assembly of multiple parts. ${ }^{5}$

Using the latest version of these printers, we have been able to create models that are accurate both anatomically and spatially. ${ }^{9}$ These models duplicate actual tissue and thus provide an element of realism that has long been missing in model-aided teaching. More importantly, the models were easily reproducible once the initial programming was mastered.

These patient-specific models can be used to train surgeons to perform navigation, because the models can be registered using the patient-specific data via conventional navigation stations. The accuracy of these models was achieved using this technique with a $3 \mathrm{D}$ printer based on actual patient data, and the ability of these models to be registered to a navigation station has been previously described by Waran et al. ${ }^{10}$ After registration, the trainee can then use the model to plan the operation, including the required flap and trajectory for surgery.

These models now allow trainees to perform a number of basic neurosurgical steps in a standardized fashion, similar to other training models such as microdissection and suturing. A trainee can perform almost an entire basic procedure rather than learning it in parts by being trained on an actual patient.

In our effort to improve cost-efficiency, the models are presently printed in 2 segments. The base segment, consisting of facial features and the head, is only required for navigation registration purposes; thus it is printed of only a single material, and this can be reused. The second insert segment on which trainees operate is printed using multiple materials, and this is slotted into the first segment. The second segment is discarded after an "operation" is completed and a new one is inserted when a new trainee needs to use it. Both segments are printed using the same patient's data. In using this technique, the reusable base portion presently costs approximately US $\$ 2000$, and the disposable-insert surgical portion costs US $\$ 600$ to reproduce.

For the purpose of this project a total of 4 base (navigation) segments and 4 disposable-insert segments were printed to create a complete head with tumor. However, there is no limit on the number of models that can be reproduced once the primary patient data have been processed and the various required characteristics have been programmed into the printer.

As 3D printer technology improves, these machines will provide the possibility for newer, more complex models to be created, allowing an improved training experience. In the future it may be possible to simulate the handling characteristics of brain parenchyma itself, allowing trainees to perform actual dissection and retraction.

\section{Conclusions}

The use of the new-generation 3D printer yields the creation of more realistic models with multiple tissues, which allows an improved training experience.

\section{Acknowledgment}

We thank the University of Malaya for funding support for this research via the High Impact Research Grant (H-5000100-A000026) awarded to Professor Waran. Neither the grant committee nor the University of Malaya had a direct role in the study design; in the collection, analysis, and interpretation of data; in the writing of the report; or in the decision to submit the paper for publication.

\section{Disclosure}

The authors report no conflict of interest concerning the mate-

\section{TABLE 1: Tissue characteristics of surgical model made with a multimaterial 3D printer}

\begin{tabular}{|c|c|c|c|}
\hline Tissue & Desired Character & $\begin{array}{l}\text { Performance } \\
\text { Assessment }\end{array}$ & Comments \\
\hline skin & pliability & good & feels stiff \& cadaveric \\
\hline bone & $\begin{array}{l}\text { texture \& handling w/ craniotome perfo- } \\
\quad \text { rator \& cutter }\end{array}$ & good & $\begin{array}{l}\text { behaves very much like natural bone; perforator stops at dural } \\
\text { interface \& foot plate of cutter is able to separate dural layer } \\
\text { from bone when used }\end{array}$ \\
\hline dura & texture $\&$ handling for cutting \& suturing & good & lacks dural vessels \\
\hline tumor & consistency & good & $\begin{array}{l}\text { allows easy identification from normal brain, suction \& biopsy pos } \\
\text { sible; however, tumor had only a single consistency throughout }\end{array}$ \\
\hline $\begin{array}{l}\text { accuracy of navigation } \\
\text { for planning }\end{array}$ & & excellent & accurate registration \& planning possible \\
\hline
\end{tabular}


rials or methods used in this study or the findings specified in this paper.

Author contributions to the study and manuscript preparation include the following. Conception and design: Waran. Acquisition of data: Narayanan, Karuppiah. Drafting the article: Narayanan, Karuppiah. Critically revising the article: all authors. Reviewed submitted version of manuscript: all authors. Approved the final version of the manuscript on behalf of all authors: Waran. Study supervision: Waran.

\section{References}

1. D’Urso PS, Anderson RL, Weidmann MJ, Redmond MJ, Hall BI, Earwaker WJ, et al: Biomodelling of skull base tumours. J Clin Neurosci 6:31-35, 1999

2. D'Urso PS, Thompson RG, Atkinson RL, Weidmann MJ, Redmond MJ, Hall BI, et al: Cerebrovascular biomodelling: a technical note. Surg Neurol 52:490-500, 1999

3. Izatt MT, Thorpe PL, Thompson RG, D'Urso PS, Adam CJ, Earwaker JW, et al: The use of physical biomodelling in complex spinal surgery. Eur Spine J 16:1507-1518, 2007

4. Kimura T, Morita A, Nishimura K, Aiyama H, Itoh H, Fukaya $\mathrm{S}$, et al: Simulation of and training for cerebral aneurysm clipping with 3-dimensional models. Neurosurgery 65:719-726, 2009

5. Mori K, Yamamoto T, Nakao Y, Esaki T: Development of artificial cranial base model with soft tissues for practical education: technical note. Neurosurgery 66 (6 Suppl Operative): 339-341, 2010

6. Müller A, Krishnan KG, Uhl E, Mast G: The application of rapid prototyping techniques in cranial reconstruction and preoperative planning in neurosurgery. J Craniofac Surg 14: 899-914, 2003

7. Paiva WS, Amorim R, Bezerra DA, Masini M: Aplication of the stereolithography technique in complex spine surgery. Arq Neuropsiquiatr 65:443-445, 2007

8. Rengier F, Mehndiratta A, von Tengg-Kobligk H, Zechmann
$\mathrm{CM}$, Unterhinninghofen $\mathrm{R}$, Kauczor $\mathrm{HU}$, et al: 3D printing based on imaging data: review of medical applications. Int J CARS 5:335-341, 2010

9. Waran V, Menon R, Pancharatnam D, Rathinam AK, Balakrishnan YK, Tung TS, et al: The creation and verification of cranial models using three-dimensional rapid prototyping technology in field of transnasal sphenoid endoscopy. Am J Rhinol Allergy 26:e132-e136, 2012

10. Waran V, Pancharatnam D, Thambinayagam HC, Raman R, Rathinam AK, Balakrishnan YK, et al: The utilization of cranial models created using rapid prototyping techniques in the development of models for navigation training. J Neurol Surg A Cent Eur Neurosurg [epub ahead of print], 2013

11. Wurm G, Lehner M, Tomancok B, Kleiser R, Nussbaumer K: Cerebrovascular biomodeling for aneurysm surgery: simulation-based training by means of rapid prototyping technologies. Surg Innov 18:294-306, 2011

12. Wurm G, Tomancok B, Pogady P, Holl K, Trenkler J: Cerebrovascular stereolithographic biomodeling for aneurysm surgery. Technical note. J Neurosurg 100:139-145, 2004

Manuscript submitted May 23, 2013.

Accepted November 4, 2013.

Please include this information when citing this paper: published online December 10, 2013; DOI: 10.3171/2013.11.JNS131066.

Supplemental online information:

Video: http://mfile.akamai.com/21490/wmv/digitalwbc.download. akamai.com/21492/wm.digitalsource-na-regional/jns13-1066_ video_1.asx (Media Player).

http://mfile.akamai.com/21488/mov/digitalwbc.download. akamai.com/21492/qt.digitalsource-global/jns13-1066_video_1. mov (Quicktime).

Address correspondence to: Vicknes Waran, F.R.C.S.(Neurosurgery), Division of Neurosurgery, Department of Surgery, Faculty of Medicine, University of Malaya, Kuala Lumpur, Malaysia. email: cmvwaran@gmail.com. 